\title{
Pain management in cancer patients in the main hospitals in Mozambique
}

\author{
Emilia Pinto $^{1,2}$, Ferraz Gonçalves ${ }^{1,3}$, Jahit Sacarlal $^{4}$, Luisa Castro ${ }^{5,6}$, Guilhermina Rego $^{1}$ \\ ${ }^{1}$ School of Medicine, Porto University, Porto, Portugal; ${ }^{2}$ Pain Unit and Palliative Care Service, Maputo Central Hospital, Maputo, Mozambique; \\ ${ }^{3}$ Palliative Care Service, Portuguese Oncology Institute, Porto, Portugal; ${ }^{4}$ School of Medicine, Universidade Eduardo Mondlane, Maputo, \\ Mozambique; ${ }^{5}$ School of Health of the Polytechnic of Porto, Porto, Portugal; ${ }^{6}$ Center for Health Technology and Services Research (CINTESIS), \\ University of Porto, Porto, Portugal \\ Contributions: (I) Conception and design: E Pinto, F Gonçalves, G Rego; (II) Administrative support: E Pinto, J Sacarlal, L Castro, G Rego; (III) \\ Provision of study materials or patients: E Pinto; (IV) Collection and assembly of data: E Pinto; (V) Data analysis and interpretation: E Pinto, L \\ Castro; (VI) Manuscript writing: All authors; (VII) Final approval of manuscript: All authors. \\ Correspondence to: Emilia Pinto. Faculdade de Medicina Porto University, Rua Dr. Plácido da Costa, 4200-450 Porto, Portugal. \\ Email: emiquidade@gmail.com.
}

Background Pain is the most feared and distressing symptom in palliative care. In advanced stages of cancer, its incidence is $70-80 \%$. In Mozambique there is little published information concerning to the prevalence, intensity, and pain's management in cancer patients.

Methods: A cross-sectional observational study was conducted between August 2018 and January 2019, in Mozambique's main hospitals, and in the only hospital with an isolated provision of palliative care service. The analyzed data included demographic data, pain intensity and its treatment. The Pain Management Index was used to calculate the adequacy of the analgesia.

Results: A total of 294 patients were included. The mean patients' age was 46.1 years old. Concerning to pain, $83.7 \%$ of the patients had pain, most of them moderate to severe pain. The prevalence of pain was frequent in women mainly in cervical cancer $(84.3 \%)$ and in men with Kaposi sarcoma (80\%). The main analgesic used for severe pain was paracetamol, and it was used alone in $40.9 \%$ of the patients. Morphine was used in $8.1 \%$ and adjuvants less than $10 \%$. Pain Management Index was negative for $68.7 \%$ of the sample, meaning an inadequate analgesia. Significant differences were found in Pain Management Index levels between hospitals.

Conclusions: The prevalence of pain in the main health institutions in Mozambique is high. Paracetamol was the analgesic most used in severe pain. Further studies are needed to understand the main reasons of patients' suffering.

Keywords: Cancer pain; opioids; pain management index; palliative care

Submitted Oct 12, 2020. Accepted for publication Dec 31, 2020.

doi: 10.21037/apm-20-2009

View this article at: http://dx.doi.org/10.21037/apm-20-2009

\section{Introduction}

Mozambique is a low-income country with a gross domestic product per capita of 460 USD per year, and about $46 \%$ of the population below the poverty line (1). Financial resources, according to the Mozambique Health Sector Strategic Plan 2013-17, were very limited, only about 7\% of the national budget was spent on health. Expenditure per capita on health in Mozambique was only about 21 USD per year, and it was much less than the World Health Organization (WHO) recommendation of a minimum of 44 USD (2).

Adequate pain relief is considered as a human right by different organizations of health professionals $(3,4)$. According to the International Council on Narcotic Control (INCB), opioids are indispensable in the management of 
moderate to strong pain, and about $80 \%$ of the world's population, most in developing countries lack of access to strong analgesia. The legal and policy restrictions negatively affect the opioids' availability in same African countries mainly in Mozambique, Zimbabwe and Swaziland (5).

In most of the low-income countries the majority of cancer patients are diagnosed with advanced-stage disease, and the only realistic treatment option is pain relief and palliative care (6). When the disease cannot be treated even with the best available treatment alternatives, what remains important is symptom management and providing comfort care to these patients. In developing countries, the incidence of cancer pain in advanced stages is $70-80 \%$ (7).

We aim to describe the prevalence, intensity, and pain management in Mozambican oncologic patients in the 3 main hospitals and in the only provincial hospital with an isolated provision of palliative care service. We present the following article/case in accordance with the STROBE reporting checklist (available at http://dx.doi.org/10.21037/ apm-20-2009).

\section{Methods}

A cross-sectional observational study was conducted between August 2018 and January 2019, in Mozambique's main hospitals namely, Maputo Central Hospital ( $\mathrm{MCH})$, Nampula Central Hospital (NCH), Beira Central Hospital $(\mathrm{BCH})$, and Xai-Xai Provincial Hospital (XXPH). The latter is the main hospital in the only province of the country that provides a standalone palliative care service. This is the reason why it was included in the study, even not being a big hospital as the others, but to see if there is any difference in pain management. Nevertheless, palliative care has been provided in the reference hospital in the country.

Sample size was calculated for the estimate of proportions based on the combined inpatient capacity of each hospital using a confidence interval of $95 \%$ and a margin of error of $5 \%$, generating an estimated minimum sample size of 344 from a population of 3,264 patients in the 4 hospitals. A consecutive sample of cancer patients were recruited: 158 participants from $\mathrm{MCH}, 101$ from $\mathrm{BCH}$, 56 from $\mathrm{NCH}$ and 29 from XXPH, until the sample size was reached, (in Xai-Xai Provincial Hospital it was not reached because in this hospital there were not enough cancer patients during the period study). The services included in the study due to having the majority of oncologic patients were: Oncology, Gynecology, Gastrology, Surgery, Urology, Pain Unit, Dermatology, Otorhinolaryngology,
Maxillofacial and Ophthalmology.

Patients $\geq 14$ years old (limited age to Mozambique pediatric services), and $<18$ years with caregiver or legal representative or $\geq 18$ years able to understand the questionnaire, who agreed to participate in the study were included. Thirty-five eligible patients were excluded due to incomplete surveys (16 from $\mathrm{MCH}, 9$ from $\mathrm{BCH}, 10$ from $\mathrm{NCH})$. Additionally, 11 patients in agony were excluded ( 1 from $\mathrm{NCH}, 3$ from $\mathrm{BCH}$ and 7 from $\mathrm{MCH}$ ).

In this study, was excluded any treatment for pain relief to the patients by the research team-if a participant was identified in need of medical attention, the patient's medical team was informed.

The analyzed data comprised demographic data, pain intensity and its management.

Pain intensity was rated using a five-point verbal rating scale from none to maximum pain. The pain was classified as: 0 , no pain; 1 , mild pain; 2 , moderate pain; and 3 , severe pain. The Pain Management Index (PMI) was used to calculate the adequacy of the analgesia (8).

According to the PMI, the analgesics were classified as: 0 , no analgesics; 1 , non-opioids for mild pain (e.g., nonsteroidal anti-inflammatory or acetaminophen); 2, weak opioids for mild to moderate pain (e.g., codeine and tramadol); and 3, strong opioids for moderate to severe pain (e.g., morphine). Then, the PMI was computed by subtracting the pain level from the analgesic level. The PMI ranges from -3 (a patient receiving no analgesics with severe pain) to +3 (a patient receiving opioids for moderate to severe pain with no pain, that is, completely controlled pain). Negative scores were considered inadequate analgesia, and scores of 0 or positive indicate acceptable to good analgesia. In this study, for computing the PMI, severe and maximum pain were classified together as severe.

\section{Statistical analysis}

Statistical analysis was performed using SPSS statistical software, version 25 (IBM Corp, Armonk, NY, USA). Regarding descriptive statistics, absolute and relative frequencies were used for categorical variables, means with $95 \%$ confidence intervals ( $95 \%$ CI) for normally distributed continuous variables and medians with interquartile interval [Q1, Q3] otherwise. Inferential statistics were employed according to the level of measurement: $\chi^{2}$ for independence of categorical variables (or Fisher exact test if more than 20\% of expected counts were less than 5), Mann-Whitney and Kruskal Wallis for ordinal variables distributions comparison 
Table 1 Demographics data for the 294 patients

\begin{tabular}{lc}
\hline Sample characteristics & $\mathrm{n}(\%)$ \\
\hline Gender & $177(60.2)$ \\
Female & $117(39.8)$ \\
Male & $46.1[44.4,47.8]$ \\
Average age [95\% Cl] & \\
Age group (years old) & $62(21.0)$ \\
$18-34$ & $144(49.5)$ \\
$35-54$ & $86(29.6)$ \\
Above 55 & \\
Participants by Hospital & $143(48.6)$ \\
MCH & $45(15.3)$ \\
NCH & $92(31.3)$ \\
BCH & $14(4.8)$ \\
XXPH
\end{tabular}

$\mathrm{MCH}$, Maputo Central Hospital; NCH, Nampula Central Hospital; $\mathrm{BCH}$, Beira Central Hospital; XXPH, Xai-Xai Provincial Hospital.

between 2 or more groups, respectively. In all tests, $\mathrm{P}$ values were considered significant if less or equal to 0.05 .

\section{Ethics and consent to participate}

All purposes objectives were explained to all participants, and informed consent in paper were given. Signed written consent was requested to all participants. Patients under 18 years old, consent was requested from the caregiver or legal representative.

The study was conducted in accordance with the Declaration of Helsinki (as revised in 2013). The study was approved by the Institutional Committee of Bioethics for Health of the Faculty of Medicine \& Maputo Central Hospital with number CIBS FM\&HCM/08/2018 and by the Bioethics Committee of the Faculty of Medicine of the University of Porto, and informed consent was taken from all the patients.

\section{Results}

A total of 294 patients were included, corresponding to a margin of error of $5.45 \%$. The study had an $85 \%$ response rate (294/344 forms fully completed): 143 respondents (90.5\%) from $\mathrm{MCH}, 92$ (91.1\%) from BCH, 45 (80.3\%)
Table 2 Most common cancers distribution n (\%), by gender (N=294)

\begin{tabular}{lccc}
\hline Type of cancer & Female $(\mathrm{n}=177)$ & Male $(\mathrm{n}=117)$ & Total \\
\hline Cervix cancer & $83(46.9)$ & - & $83(28.2)$ \\
Kaposi sarcoma & $12(6.8)$ & $35(29.9)$ & $47(16.0)$ \\
Breast cancer & $25(14.1)$ & $1(0.9)$ & $26(8.8)$ \\
Prostate cancer & - & $18(15.4)$ & $18(6.1)$ \\
Rectal cancer & $7(4.0)$ & $4(3.4)$ & $11(3.7)$ \\
Bladder cancer & $6(3.4)$ & $4(3.4)$ & $10(3.4)$ \\
Mandibular cancer & $2(1.1)$ & $8(6.8)$ & $10(3.4)$ \\
Esophageal cancer & $4(2.3)$ & $6(5.1)$ & $10(3.4)$ \\
Others & $38(21.5)$ & $41(35.0)$ & $79(26.9)$ \\
\hline
\end{tabular}

from $\mathrm{NCH}$ and XXPH with 14 (48.3\%). Patient's average age $[95 \% \mathrm{CI}]$ was $46.1[44.4,47.8]$ years old and $60.2 \%$ were female (see Table 1). The most prevalent cancers were: cervical cancer 83 (46.9\%), breast cancer 25 (14.1\%) and Kaposi sarcoma 12 (6.8\%) in women, and Kaposi sarcoma $35(29.9 \%)$, prostate cancer $18(15.4 \%)$ and mandibular cancer $8(6.8 \%)$ in men (see Table 2).

Pain was frequent mainly in cervical cancer $(84.3 \%)$ in women, and Kaposi sarcoma (80\%) in men (see Figure 1 and Figure 2). All patients with head and neck's cancer, lung, abdominal, epidermoid cancers and osteosarcoma, reported intensive pain.

Of the total of 177 women, $84.2 \%$ had pain, most of them moderate $(38.4 \%)$ to severe $(27.7 \%)$ pain, mainly in cervix, breast cancer and Kaposi sarcoma. In the 117 men of our sample, $82.9 \%$ reported pain, mostly moderate $(31.6 \%)$ and severe pain $(33.3 \%)$, and the most frequent cancer related pain resulted from prostate, Kaposi sarcoma and jaw cancer.

Regarding Kaposi sarcoma, the most prevalent cancer present in both genders, there were no significant differences in pain (dichotomous variable) reported by gender $(\mathrm{P}=0.435)$ nor in the distribution of pain intensity by gender $(\mathrm{U}=171.5 ; \mathrm{P}=0.355)$.

For pain relief, the non-opioid analgesic most used was paracetamol (35.7\%). The weak opioids used by patients who reported pain were tramadol $(6.5 \%)$ and codeine (4.1\%); morphine $(8.1 \%)$ was the only strong opioid used (see Figure 3). Paracetamol was used alone in $40.9 \%$ of the patients with severe pain. Morphine was mainly prescribed to severe pain $(75 \%)$ and tramadol to moderate and severe 


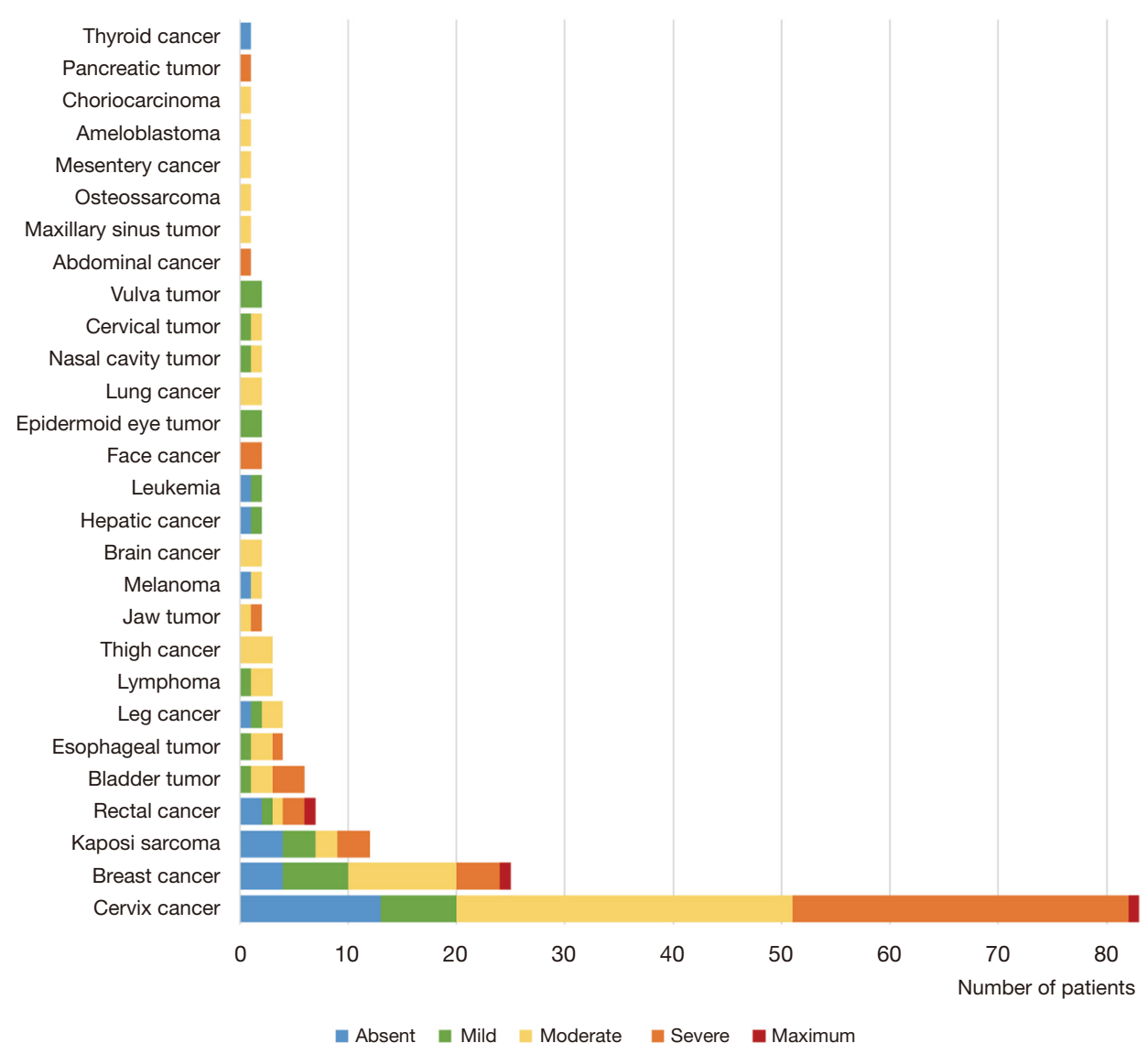

Figure 1 Pain intensity by cancer diagnosis in women.

pain in $43.8 \%$ each. XXPH was the hospital were most of the patients were doing morphine for moderate to severe pain relieve (see Figure 4). The adjuvants were little used (9.5\%): corticosteroids (prednisolone and dexamethasone) in $4.4 \%$ and antidepressant (amitriptyline) in $5.1 \%$ of the patients (see Table 3). No invasive techniques were used to control pain.

PMI was negative for $68.7 \%$ of the sample, meaning an inadequate analgesia, and $31.3 \%$ were 0 -positive meaning acceptable to good analgesia (see Figure 5). Significant differences were found in PMI levels between hospitals $\left[\chi_{K W}^{2}(3)=12.909, \mathrm{P}=0.005, \mathrm{n}=294\right]$. After multiple comparisons, it was found that Xai-Xai hospital had a different PMI distribution [median $=0$ and IQI $=(-0.5,1)$ ] than $\mathrm{MCH}[\mathrm{P}=0.002$, median $=-1$ and $\mathrm{IQI}=(-2,0)], \mathrm{NCH}$ $[\mathrm{P}=0.015$, median $=-1$ and $\mathrm{IQI}=(-2,0)]$ and $\mathrm{BCH}[\mathrm{P}=0.019$, median $=-1$ and $\mathrm{IQI}=(-2,0)]$.

There was also a significant difference $\left[\chi^{2}(3)=16.231\right.$; $\mathrm{P}=0.001]$ between the proportions of adequate/inadequate analgesia in the 4 hospitals. The most inadequate analgesia was found at the reference hospital of the country, Maputo Central Hospital (86.8\%), Nampula Central Hospital (100\%) and Beira Central Hospital (78.5\%). Overall, only $17.9 \%$ of the patients had adequate analgesia (see Table 4 and Figure 6).

The main co-morbidity was Human Immunodeficiency Virus-Acquired Immunodeficiency Syndrome (HIV-SIDA) in $41.8 \%$ and $74 \%$ of them were doing antiretroviral treatment.

All Kaposi sarcoma's patients in both sexes, with or without pain were HIV positives.

Of the 98 patients with moderate pain, $44.9 \%$ were HIV positive and of the 86 patients with severe pain, $33.7 \%$ were HIV positive. There were no significant differences in the proportion of HIV patients between the group of moderate and severe pain $\left[\chi^{2}(1)=2.391 ; \mathrm{P}=0.122\right]$. Moderate-severe pain was present in $61.8 \%$ of HIV patients.

Of the 63 women with moderate pain, $41.3 \%$ were HIV positive, and of the 48 women with severe pain, $41.7 \%$ were HIV positive. There was no significant difference in 


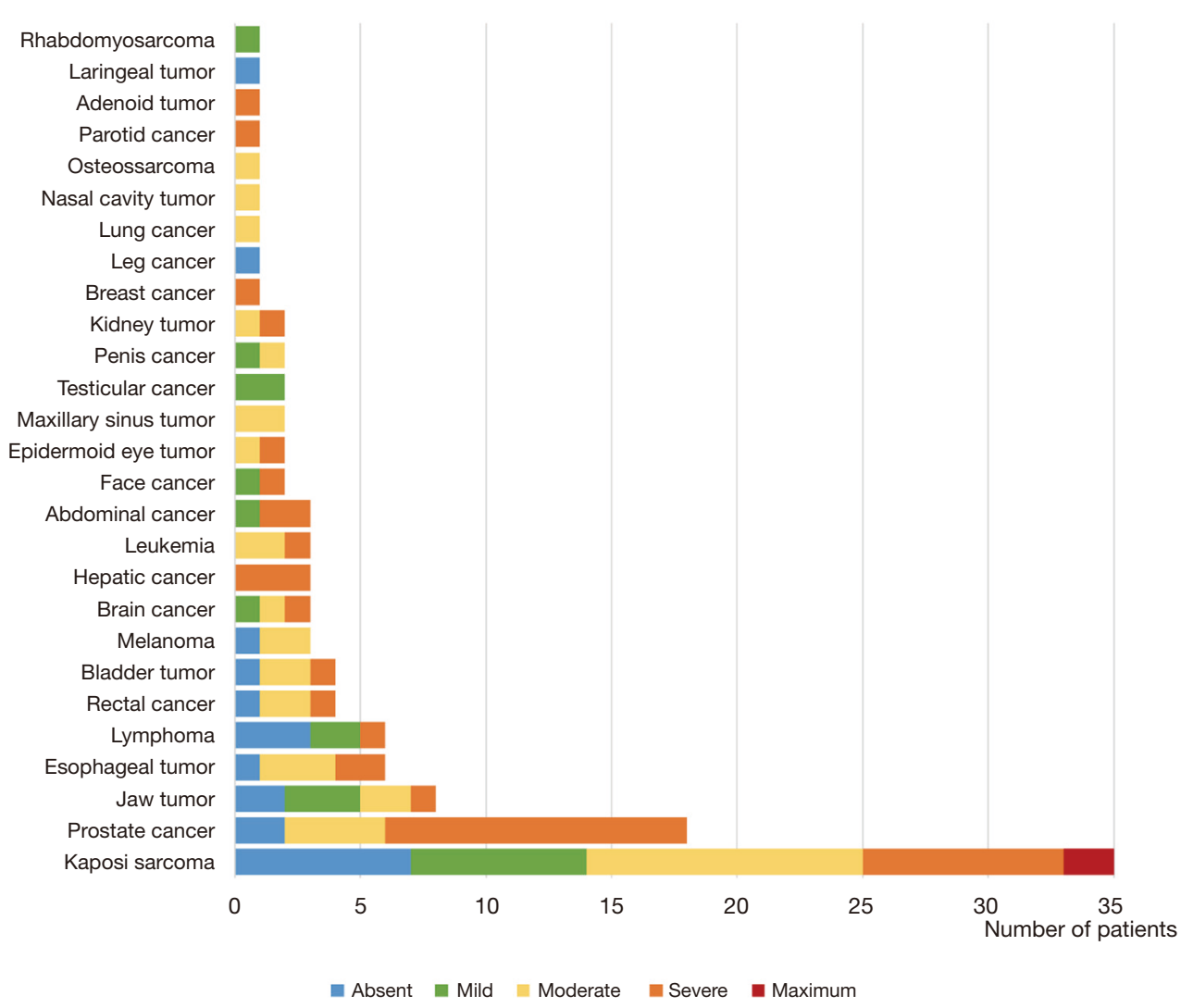

Figure 2 Pain intensity by cancer diagnosis in men.

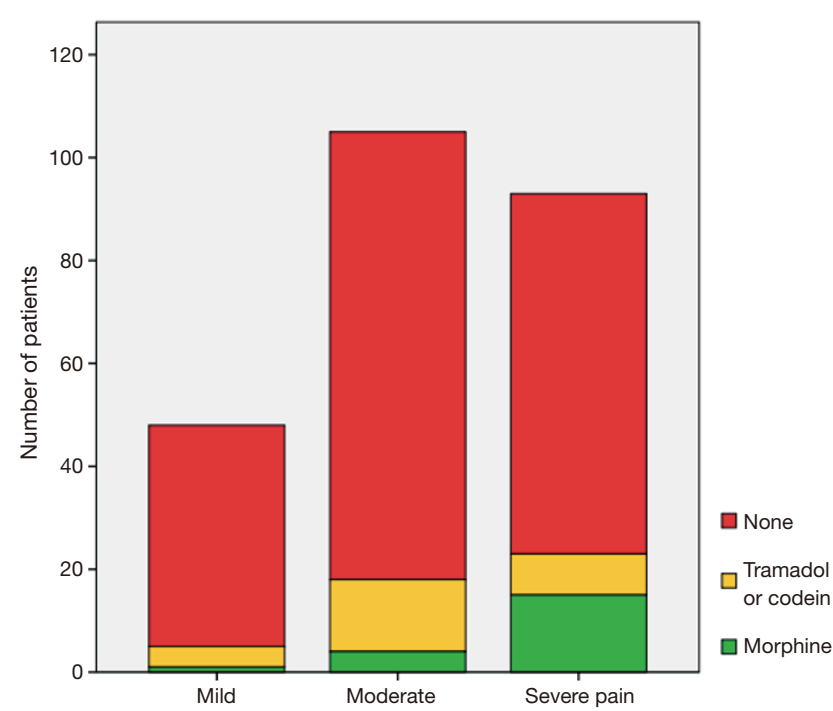

Figure 3 Number of patients receiving tramadol or codeine and morphine by pain's intensity in all hospital. the proportion of women with HIV positive between the moderate pain group and the severe pain group $\left[\chi^{2}(1)=0.002\right.$; $\mathrm{P}=0.966]$.

Of the 35 men with moderate pain, 51.4\% were HIV positive and of the 38 men with severe pain $23.7 \%$ were HIV positive. There were significant differences in the proportion of men with HIV positive between the moderate pain group and the severe pain group $\left[\chi^{2}(1)=6.017\right.$; $\mathrm{P}=0.014]$.

\section{Discussion}

To our knowledge, this was the first study to assess the prevalence, intensity and pain management in cancer patients in Mozambique. The analysis comprised a total of 294 patients, from the 3 main hospitals in the north, center and south of the country, and in Xai-Xai Provincial Hospital 

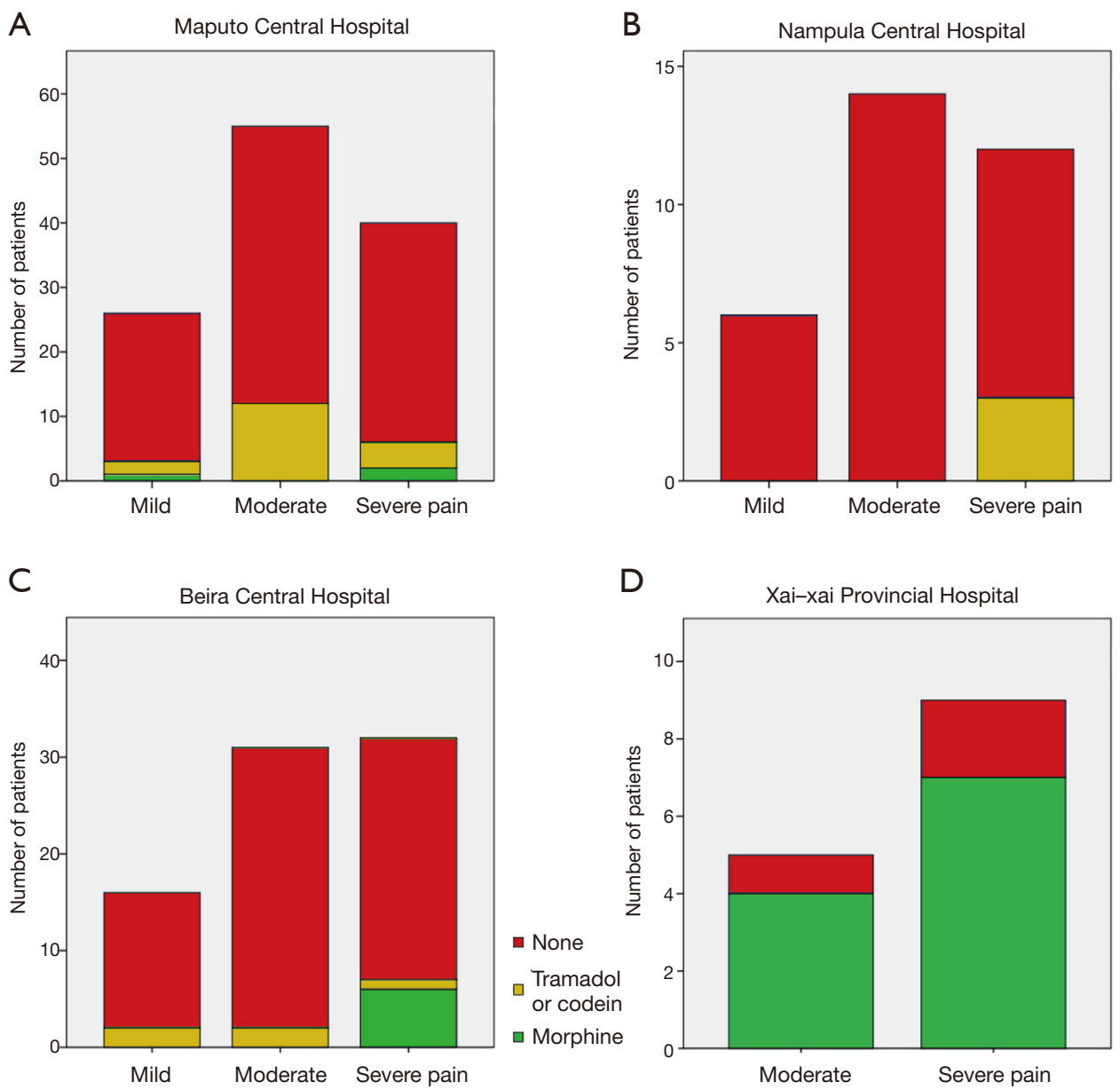

Figure 4 Number of patients receiving tramadol or codeine and morphine by pain's intensity in each hospital: Maputo Central Hospital (A), Nampula Central Hospital (B), Beira Central Hospital (C) and Xai-Xai Provincial Hospital (D).

Table 3 Frequencies, $n$ (\%), of analgesic's class and adjuvants administered to patients in pain, by hospital $(\mathrm{n}=246)$

\begin{tabular}{|c|c|c|c|c|c|}
\hline $\begin{array}{l}\text { Analgesics and } \\
\text { adjuvants }\end{array}$ & $\mathrm{MCH}(n=121)$ & $\mathrm{NCH}(\mathrm{n}=32)$ & $\mathrm{BCH}(\mathrm{n}=79)$ & $\mathrm{XXPH}(\mathrm{n}=14)$ & Total $(n=246)$ \\
\hline NSAID & $0(0)$ & $2(6.3)$ & $12(15.2)$ & $0(0)$ & $14(5.7)$ \\
\hline Codeina & $6(5)$ & $0(0)$ & $4(5.1)$ & $0(0)$ & $10(4.1)$ \\
\hline Tramadol & $12(9.9)$ & $3(9.4)$ & $1(1.3)$ & $0(0)$ & $16(6.5)$ \\
\hline Dexamethasona & $4(3.3)$ & $0(0)$ & $1(1.3)$ & $0(0)$ & $5(2)$ \\
\hline Prednisolone & $1(0.8)$ & $0(0)$ & $6(7.6)$ & $0(0)$ & $7(2.8)$ \\
\hline Amitriptilyne & $2(1.7)$ & $0(0)$ & $2(2.5)$ & $10(71.4)$ & $14(5.7)$ \\
\hline
\end{tabular}

NSAID, Non-Steroidal Anti-Inflammatory Drugs; $\mathrm{MCH}$, Maputo Central Hospital; NCH, Nampula Central Hospital; BCH, Beira Central Hospital; XXPH, Xai-Xai Provincial Hospital. 


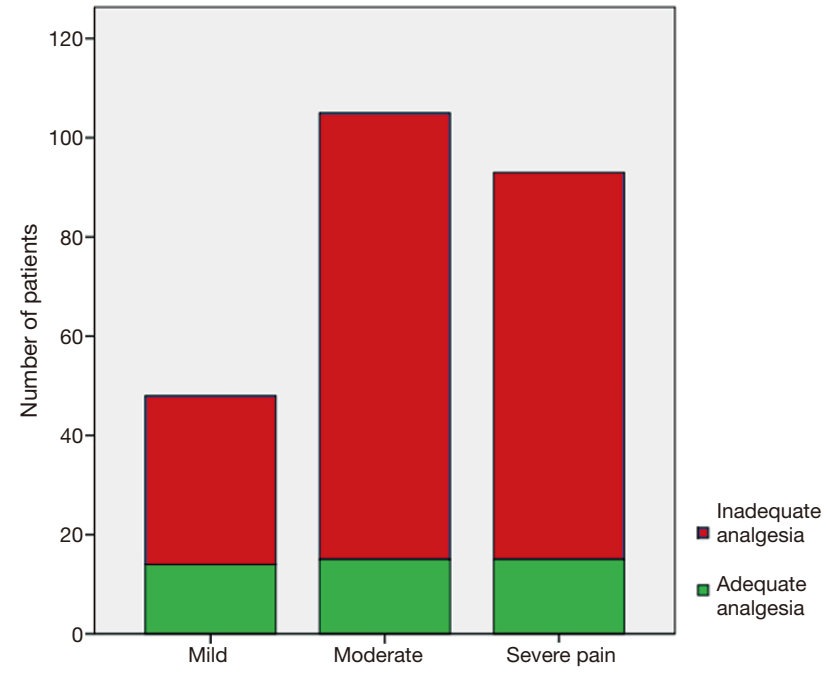

Figure 5 Number of patients with adequate and inadequate analgesia by pain's intensity.

(the only province of the country with isolated provision of palliative care services).

The prevalence of cancer pain was $83.6 \%$ mainly in cervix and breast cancer in women and Kaposi sarcoma and prostate cancer in men. Most of the patients had moderate to severe pain, and there were no significant differences in pain reported by gender in Kaposi sarcoma, in any assessment of the pain involved in the study. Paracetamol was the main analgesic used for severe pain. Morphine and adjuvants was used most in Xai-Xai Provincial Hospital. Most of the patients had an inadequate analgesia and significant differences were found in PMI levels between hospitals. Inadequate analgesia was found in the reference hospital of the country-MCH. Moderate-severe pain was present in $61.8 \%$ of HIV patients.

According to WHO's projections for 2030, the 2 main cancer diagnoses in women (cervical and breast cancer), and the $2^{\text {nd }}$ and $3^{\text {rd }}$ in men (prostate and liver cancer), in Maputo-Mozambique will be the main causes of cancer mortality in Sub-Saharan Africa (9-11). Cervical cancer among females were the leading cause of cancer deaths in Mozambique with 42/100,000 people $(12,13)$.

The type of cancer, treatments performed or ongoing and characteristics of the patient determine the intensity of the pain and its effects. The prevalence and severity of pain depends on the progression of the disease (3).

According to the WHO guidelines for cancer pain's management, it is considered adequate management when there is a congruence between the patient's reported level of pain and the potency of prescribed analgesic drug (based on the analgesic ladder). The pain-management index compares the most potent analgesic prescribed for a patient with that patient's reported levels of pain (14), and it measures the health care provider's response to a patient's pain.

The global context of opioids consumption shows that Australia, Canada, New Zealand, the United States, and several European countries account for more than $90 \%$ of the global consumption of opioid analgesics. Furthermore, the consumption of opioids in most Asian countries continues to increase at a slower rate than global averages (15). Opioid consumption is an indicator of palliative care services in a country, and morphine is a WHO essential medicine, however it is drastically limited, or absent, in many developing countries were its consumption is only $6 \%$ of global opioid consumption $(3,16)$. In India, less than $1 \%$ of the population has access to pain relief and palliative care (17). According to the International Narcotics Control Council (INCB), about 80\% of the world population, the majority in developing countries, do not have access to strong analgesia $(5,18)$.

Adequate pain relief can be achieved in more than $75 \%$ of patients using simple WHO analgesic ladder such as techniques, opioids, non-opioid analgesics, and adjuvant medications (19).

Many health professionals in developing countries are focused on treating diseases that cause pain, rather than to relieve the pain itself, and this contributes greatly to inadequate pain relief (20).

The main barriers that interfere with adequate pain management in Africa are problems related to health-care system, health professionals and patients (21). One of the main gap between pain management needs and what was provide was the health-care system; many governments remain passive while people is suffering. Part of this passivity contributes to the chain: absence of policies or guidelines for pain's treatment or palliative care's guidelines for health professionals and insufficient efforts to ensure morphine access and availability for those who need it (6).

In Mozambique, the legal and policy restrictions negatively affect the opioids' availability (5). Comparing to Uganda's consumption (100 kg/42 million population), Mozambique's consumption was only $4.7 \mathrm{~kg}$ out of the expected $322 \mathrm{~kg}$ per year for 26 million inhabitants in 2015.

The obstacles to the use of opioids in Mozambique also include: inadequate knowledge, lack of information and negative attitudes towards controlled substances (22).

In Mozambique compared to other countries, did not have another alternatives such as oxycodone, hydromorphone and 
Table 4 Frequencies n (\%), of analgesia adequacy by hospital and gender ( $\mathrm{N}=246)$

\begin{tabular}{|c|c|c|c|c|c|c|}
\hline Hospital & \multicolumn{2}{|c|}{ Female $(n=149)$} & \multicolumn{2}{|c|}{ Male $(n=97)$} & \multicolumn{2}{|c|}{ Total } \\
\hline $\mathrm{NCH}$ & $14(100.0)$ & $0(0.0)$ & $18(100.0)$ & $0(0.0)$ & 32 (100.0) & $0(0.0)$ \\
\hline Total & $117(78.5)$ & 32 (21.5) & 85 (87.6) & 12 (12.4) & $202(82.1)$ & 44 (17.9) \\
\hline
\end{tabular}

$\mathrm{MCH}$, Maputo Central Hospital; NCH, Nampula Central Hospital; BCH, Beira Central Hospital; XXPH, Xai-Xai Provincial Hospital.
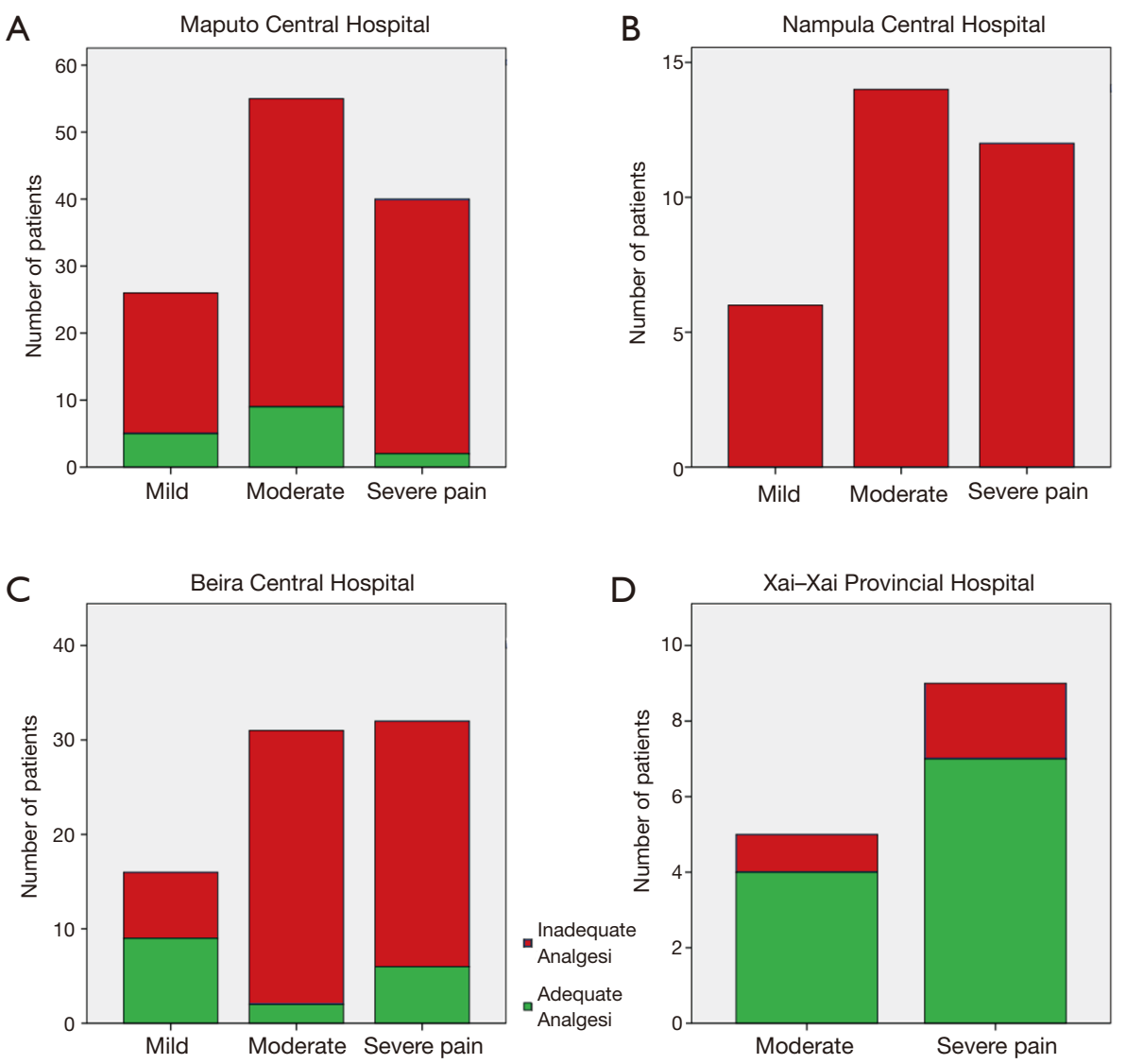

Figure 6 Number of patients with adequate and inadequate analgesia by pain's intensity (mild, moderate and severe) in each hospital: Maputo Central Hospital (A), Nampula Central Hospital (B), Beira Central Hospital (C) and Xai-Xai Provincial Hospital (D).

transdermal opioids presentations as an essential medicines. It could be found in some private pharmacies and hospitals, however they were very expensive for the most of the population.

Access to health care in Mozambique was limited by distances to the nearest health service provider and the few health professionals, as well as frequent stock outs of medicines in general and opioids in particular. The estimation method for Mozambique's national annual opioid requirements was consumption-based and it 
considered only the past year's consumption and existing stocks. Studies carried out in Mozambique already pointed to a low consumption of morphine, and this limited access and availability of opioids, increases patients' suffering and deeply impacts their quality of life.

This study revealed a slightly higher pain's prevalence compared to world statistics that point to $70-80 \%$ for moderate-severe pain in cancer patients, and most of them in developing countries (7).

The Xai-Xai Provincial Hospital although being small and with simple size, demonstrated better pain's control than other hospitals. The training actions on pain management and palliative care developed in this hospital contributed significantly to better symptomatic pain control in oncologic patients. Unrelieved pain negatively affects the patient's quality of life and family economy; it also influences a patient's ability to withstand treatment changes and overloads the healthcare system (23).

In 2012, in MCH-Pain Unit, paracetamol was also the most commonly used drug (33.9\%) and morphine was used in $10.2 \%$ of cancer patients $(24,25)$. The OMS guidelines address first-line treatment with strong opioids for patients who have been assessed as requiring pain relief at the third level of the WHO pain ladder (26).

Along with opioids, adjuvant drugs such as antidepressants and anticonvulsants, play an important role in pain management. In these hospitals, amitriptyline and corticosteroids were less used for pain control.

Significant differences were found in PMI levels between hospitals in our study. It was at the Xai-Xai Provincial Hospital that the highest PMI levels were observed, with adequate levels for $78.6 \%$ of its sample patients while the remaining hospitals had adequate PMI levels in less than $21.5 \%$ of sample patients. In Portugal, the PMI results were acceptable to good (25).

Pain can also be relieved by the modification of the disease process, when appropriate, with surgery, chemotherapy, and radiotherapy (27). Although Mozambique has all these techniques, they are inaccessible to many patients, because most of them usually get to the hospital at an advanced stage of illness, and others live in rural areas where these services are non-existent.

Pain is a common symptom in people living with HIV/ AIDS. Several studies claim that $60-80 \%$ of HIV-AIDS patients report pain in an advanced stage of the disease. They may experience pain as (I) a direct result of the viral replication mechanisms on the peripheral or central nervous systems; (II) pain may be due to immune suppression and resultant opportunistic infections; or (III) pain may arise because of the side effects of the continuous anti - retroviral treatment $(3,28)$. Close to half of the oncologic patients in this study had HIV-AIDS as the main co-morbidity, and most of them $(74 \%)$ were taking antiretroviral treatment. Most of these patients were moderate-severe pain's intensity related. In these patients, they may experience pain not only due to the cancer disease itself, but also concomitant infection and/or HIV treatment.

The excessive strict drug control regulations that unnecessarily prevent access to morphine or establish excessive penalties for misuse; lack of adequate supply of opioids and other drugs for pain relief, strong bureaucracy involved in terms of procurement and dispensing of opioids; the lack of training of health professionals on pain management and. palliative care as part of their training that negatively influences attitudes towards controlled substance $(3,6,15,24,29)$.

\section{Limitations}

The main limitations were:

(I) Related to the sample in Xai-Xai Provincial Hospital, we did not complete the sample because of limited time.

(II) Disparity of resources between the different hospitals in the country, which does not allow to staging for all tumors.

(III) Only 4 hospitals were surveyed, so this data may not be generalizable to the whole country.

\section{Conclusions}

The overall prevalence of pain is slightly higher than reported by other studies. Most of the oncologic patients in Maputo, Beira and Nampula Central hospitals in Mozambique, were suffering because of inadequate analgesia. Less than $10 \%$ of oncologic pain's patients in these hospitals had access to strong analgesia as morphine. Xai-Xai Provincial Hospital, (the only Provincial hospital in the country with a standalone palliative care Service) was the only hospital with adequate analgesia were all the patients with moderate to severe pain was taking morphine. We also concluded that the presence of health professionals trained and qualified in the management of pain and palliative care significantly improves the symptomatic control of patients. Further studies are needed to understand if the suffering reported by the patients is due to the lack of medicines or lack of professional's knowledge in 
pain management or both.

\section{Acknowledgments}

We would like to thank Gulbenkian Fundation grant number $\mathrm{N}^{\circ} .144879$, and Ministry of Heath of Mozambique for individual $\mathrm{PhD}$ grants' contributions.

Funding: None.

\section{Footnote}

Reporting Checklist: The authors have completed the STROBE reporting checklist. Available at http://dx.doi. org/10.21037/apm-20-2009

Data Sharing Statement: Available at http://dx.doi. org/10.21037/apm-20-2009

Conflicts of Interest: All authors have completed the ICMJE uniform disclosure form (available at http://dx.doi. org/10.21037/apm-20-2009). The authors have no other conflicts of interest to declare.

Ethical Statement: The authors are accountable for all aspects of the work in ensuring that questions related to the accuracy or integrity of any part of the work are appropriately investigated and resolved. The study was conducted in accordance with the Declaration of Helsinki (as revised in 2013). The study was approved by the Institutional Committee of Bioethics for Health of the Faculty of Medicine \& Maputo Central Hospital with number CIBS FM\&HCM/08/2018 and by the Bioethics Committee of the Faculty of Medicine of the University of Porto, and informed consent was taken from all the patients.

Open Access Statement: This is an Open Access article distributed in accordance with the Creative Commons Attribution-NonCommercial-NoDerivs 4.0 International License (CC BY-NC-ND 4.0), which permits the noncommercial replication and distribution of the article with the strict proviso that no changes or edits are made and the original work is properly cited (including links to both the formal publication through the relevant DOI and the license). See: https://creativecommons.org/licenses/by-nc-nd/4.0/.

\section{References}

1. Word Bank, Available online: https://data.worldbank.org/ country/mozambique. 2018.

2. World Health Statistics: Monitoring health for the SDGs, Available online: https://www.who.int/gho/publications/ world_health_statistics/2017/en/. 2017.

3. Human Rights Watch. "Please, do not Make us Suffer any More..." Access to Pain Treatment as a Human Right. New York: Human Rights Watch 2009.

4. Radbruch L, Payne S, de Lima L, et al. The Lisbon Challenge: acknowledging palliative care as a human right. J Palliat Med 2013;16:301-4.

5. Human Rights Watch. "Global State of Pain Treatment”. Available online: http://www.hrw.org/ru/ reports/2011/06/01/global-state-pain-treatment. 2011.

6. Paice JA, Ferrell B. The management of cancer pain. CA Cancer J Clin 2011;61:157-82.

7. Saini S, Bhatnagar S. Cancer Pain Management in Developing Countries. Indian J Palliat Care 2016;22:373-7.

8. Cleeland CS, Gonin R, Hatfield AK, et al. Pain and its treatment in outpatients with metastatic cancer. N Engl J Med 1994;330:592-6.

9. World health Organization, Projections of mortality and causes of death, 2015 and 2030, Available online: http://www.who.int/healthinfo/global_burden disease/ projections/en/. 2015.

10. Global Cancer Observatory, Available online: https://gco. iarc.fr/today/home. 2018.

11. Carrilho C, Fonte F, Tulsidás S, et al. Cancer incidence in Mozambique in 2015-2016: data from the Maputo Central Hospital Cancer Registry. Eur J Cancer Prev 2019;28:373-6.

12. Global Cancer Observatory. 2018, Available online: https://gco.iarc.fr/today/home

13. Statistical department of Maputo Central Hospital. Annual Report. 2019.

14. Cleeland C. Research in cancer pain. What we know and what we need to know. Cancer 1991;67:823-7.

15. International Narcotics Control Board. Report of the International Narcotics Control Board on the Availability of Internationally Controlled Drugs: Ensuring Adequate Access for Medical and Scientific Purposes. (2010). Available online: www.incb.org/incb/en/publications/ annual-reports/ annual-report.html.

16. De Lima L, Fau KE, Lorenz K, et al. Ensuring palliative medicine availability: the development of the IAHPC list of essential medicines for palliative care. J Pain Symptom Manage 2007;33:521-6.

17. Rajagopal MR, Joranson DE. India: opioid availability. An update. J Pain Symptom Manage 2007;33:615-22. 
18. Connor S, Sepulveda C. Global Atlas of Palliative Care at the End-of-Life. Worldwide Hospice Palliative Care Alliance, World Health Organization 2014.

19. World Health Organization. Cancer Pain Relief and Palliative Care. Geneva: World Health Organization; Expert Committee Report 1990

20. Elzahaf RA, Johnson MI, Tashani OA. The epidemiology of chronic pain in Libya: a cross-sectional telephone survey. BMC Public Health 2016;16:776.

21. Rhee JY, Garralda E, Namisango E, et al. Factors Affecting Palliative Care Development in Africa: In-Country Experts' Perceptions in Seven Countries. J Pain Symptom Manage 2018;55:1313-1320.e2.

22. Morphine Survey Report, A review of national opioid estimation procedures and supply chain mechanisms: Review done in three African countries: Swaziland, Mozambique and Zimbabwe, African Palliative Care Association 2015.

23. Duggleby W, Berry P. Transitions and Shifting Goals of Care for Palliative Patients and Their Families. Clin J

Cite this article as: Pinto E, Gonçalves F, Sacarlal J, Castro L, Rego G. Pain management in cancer patients in the main hospitals in Mozambique. Ann Palliat Med 2021;10(4):4069-4079. doi: 10.21037/apm-20-2009
Oncol Nurs 2005;9:425-8.

24. Mercadante S, Fulfaro F. World Health Organization guidelines for cancer pain: a reappraisal. Ann Oncol 2005;16 Suppl 4:iv132-135.

25. Gonçalves F, Almeida A, Antunes C, et al. A cross-sectional survey of pain in palliative care in Portugal. Support Care Cancer 2013;21:2033-9.

26. Stockler M, Fau VJ, Pillai A, et al. Acetaminophen (paracetamol) improves pain and well-being in people with advanced cancer already receiving a strong opioid regimen: a randomized, double-blind, placebo-controlled cross-over trial. J Clin Oncol 2004;22:3389-94.

27. Soyannwo OA. Cancer Pain Management for Developing Countries. IASP 2009;17.

28. Norval DA. Symptoms and sites of pain experienced by AIDS patients. S Afr Med J 2004;94:450-4.

29. World Health Organization. Access to Controlled Medications Programme: Framework. Geneva, Switzerland: World Health Organization 2007. 